\title{
Liquid Chromatographic Method for the Analysis of Brimonidine in Ophthalmic Formulations
}

\author{
A. NARENDRA* ${ }^{*}$ D. DEEPIKA ${ }^{\#}$ and M. MATHRUSRI ANNAPURNA ${ }^{\S}$ \\ *Department of Pharmaceutical analysis and Quality Assurance, \\ Roland Institute of Pharmaceutical Sciences, Berhampur, Orissa, India. \\ \#Royal College of Pharmacy and Health Sciences, Berhampur, Orissa, India. \\ §GITAM Institute of Pharmacy, GITAM university, Visakhapatnam (A.P.), India. \\ naren_angirekula@yahoo.com
}

Received 20 November 2011; Accepted 17 January 2012

\begin{abstract}
A reverse phase LC method was developed for the determination of Brimonidine in eye drops. Chromatography was carried on an Inertsil ODS 3V column (C18) using a mixture of Octane 1- sulfonic acid sodium salt $(0.02 \mathrm{M})(\mathrm{pH} 3.5 \pm 0.05)$ and acetonitrile $(64: 36 \mathrm{v} / \mathrm{v})$ as mobile phase at a flow rate of $1 \mathrm{~mL} / \mathrm{min}$ with UV detection at $254 \mathrm{~nm}$. The drug was eluted at $4.636 \mathrm{~min}$. The detector response was linear in the concentration range of $0.4-72 \mu \mathrm{g} / \mathrm{mL}$. The limit of detection and limit of quantification were found to be 0.0561 and $0.1848 \mu \mathrm{g} / \mathrm{mL}$ respectively. The proposed method was validated as per the ICH guidelines and can be applied for the routine analysis of Brimonidine in eye drops.
\end{abstract}

Keywords: Brimonidine, RP-HPLC, ICH and Eye drops.

\section{Introduction}

Brimonidine ${ }^{1}$ (BMD) (Figure 1) is an alpha adrenergic receptor agonist. It has a peak ocular hypotensive effect occurring at two hours post-dosing. Fluorophotometric studies in animals and humans suggest that Brimonidine has a dual mechanism of action by reducing aqueous humor production and increasing uveoscleral outflow. Brimonidine, chemically 5-Bromo- $N$ (4,5-dihydro-1 $H$-imidazol-2-yl) quinoxalin-6-amine has a molecular formula $\mathrm{C}_{11} \mathrm{H}_{10} \mathrm{BrN}_{5}$ and molecular weight $292.135 \mathrm{~g} / \mathrm{mol}$. Peripheral alpha 2 agonist activity results in vasoconstriction of blood vessels. This vasoconstriction may explain the acute reduction in aqueous humor flow. The increased uveoscleral outflow from prolonged use may be explained by increased prostaglandin release due to alpha adrenergic stimulation ${ }^{2}$. This may lead to relaxed ciliary muscle and increased uveoscleral outflow. 


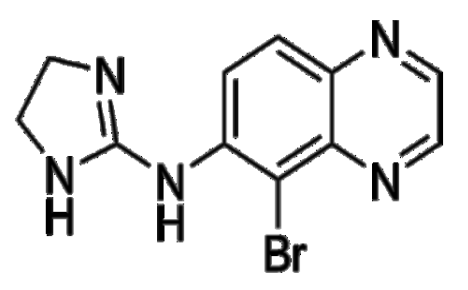

Figure 1. Chemical Structure of Brimonidine (BMD).

Literature survey reveals that very few chromatographic ${ }^{3-6}$, LC-MS $^{7-8}$ Spectrophotometric $^{9}$ and HPTLC ${ }^{10}$ methods were available for the determination of Brimonidine. In the present study an isocratic RP-HPLC method has been developed and validated for the determination of Brimonidine in ophthalmic solutions as per the ICH guidelines.

\section{Experimental}

Brimonidine was obtained as a gift sample from Cipla Ltd (India). ALPHAGAN ( $2 \mathrm{mg} / \mathrm{mL}$, $5 \mathrm{ml})$ and BRIMOPRESS eye drops $(0.2 \%, 5 \mathrm{~mL})$ were purchased from the local market. HPLC grade Acetonitrile (Merck), Octane-1 sulfonic acid sodium salt (Merck), $o$ phosphoric acid (Qualigens) and Milli-Q water were used during the study.

\section{Instrumentation}

The HPLC system consist of a Waters Alliance (Waters Corporation, MA, USA) equipped with a Waters 2695 separations module in a quaternary gradient mode and a Waters 2695 PDA detector. Data acquisition was performed by the Empower pro software operated on a Pentium ${ }^{\circledR}$ IV microprocessor. Analysis was carried out at $254 \mathrm{~nm}$ with a reversed phase Inertsil ODS $3 \mathrm{~V},(250 \times 4.0 \mathrm{~mm}, 5 \mu \mathrm{m})$ at ambient temperature.

\section{Chromatographic Conditions}

Chromatographic separations were achieved using a Inertsil ODS 3V C18 (250 X $4.6 \mathrm{~mm}$, $5 \mu)$ analytical column. The mobile phase consisted of $(0.02 \mathrm{M})$ Octane 1-sulfonic acid buffer : acetonitrile $(64: 36 \mathrm{v} / \mathrm{v})$ and $\mathrm{pH}$ adjusted to $(3.5 \pm 0.05)$ with ortho phosphoric acid that was set at a flow rate of $1.0 \mathrm{~mL} / \mathrm{min}$. The mobile phase was passed through $0.45 \mu \mathrm{m}$ membrane filter and degassed by ultra sonication before pumping into HPLC system. The flow rate was maintained at $1 \mathrm{~mL} / \mathrm{min}$ and the measurements were made at $254 \mathrm{~nm}$. The column and the HPLC system were kept in ambient temperature.

Preparation of Standard Stock solution: Accurately weighed $50 \mathrm{mg}$ of Brimonidine standard was taken in $50 \mathrm{~mL}$ volumetric flask. This was dissolved in $25 \mathrm{~mL}$ of Acetonitrile and sonicated for $10 \mathrm{mins}$, and then diluted to $50 \mathrm{~mL}$ to get $1 \mathrm{mg} / \mathrm{mL}$ standard stock solution. From the stock solution $5 \mathrm{~mL}$ was taken in $50 \mathrm{ml}$ volumetric flask and thereafter made upto $50 \mathrm{~mL}$ with mobile phase to get a concentration of $100 \mu \mathrm{g} / \mathrm{mL}$.

\section{Validation}

\section{Linearity}

Several aliquots of standard stock solutions ranging from $0.4-72 \mu \mathrm{g} / \mathrm{mL}$ of Brimonidine were prepared in different $10 \mathrm{~mL}$ volumetric flasks by diluting with mobile phase. $20 \mu \mathrm{L}$ of solutions were injected in to the HPLC system and was monitored with PDA detector at 254 nm. A representative chromatogram was shown in Figure 2. 


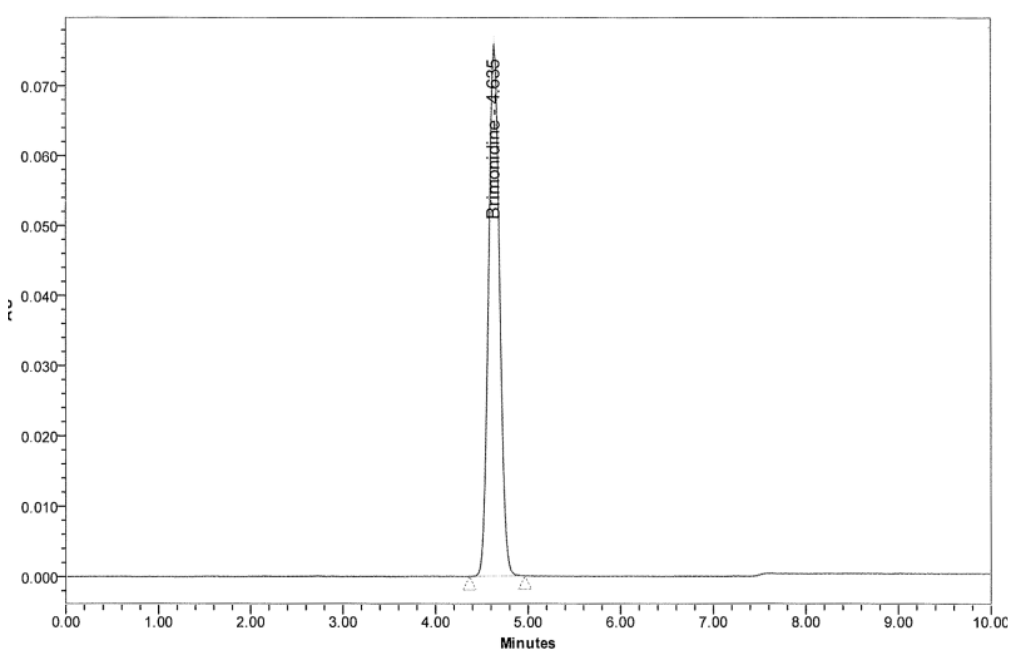

Figure 2. Typical Chromatogram of Brimonidine by HPLC $(20 \mu \mathrm{g} / \mathrm{mL})$.

The peak area of the above solutions was recorded and a Calibration graph was plotted by taking the concentration on the $\mathrm{x}$-axis and the corresponding peak area of Brimonidine on the y-axis. A straight line was obtained passing through the origin (Figure 3).

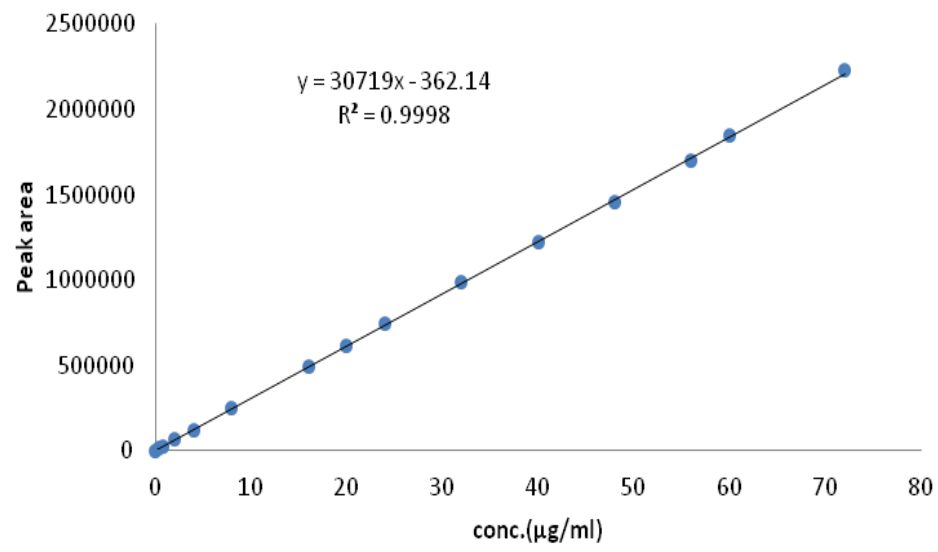

Figure 3. Calibration curve of Brimonidine by HPLC.

Assay of Commercial Formulations:

ALPHAGAN $(2 \mathrm{mg} / \mathrm{ml}, 5 \mathrm{ml})$ and BRIMOPRESS eye drops $(0.2 \%, 5 \mathrm{ml})$ were purchased from the local market and required sample solutions were made using the mobile phase and $10 \mu \mathrm{L}$ of these formulation solutions were injected into the HPLC system and the peak areas were recorded. The results are given in Table 1. 
Table 1. Analysis of commercial formulations (Eye Drops).

\begin{tabular}{|c|c|c|c|}
\hline $\begin{array}{c}\text { Commercial } \\
\text { Formulation }\end{array}$ & Labeled amount (\%) & $\begin{array}{c}\text { Amount found } \\
(\%)\end{array}$ & \% Recovery \\
\hline Brand I & 0.2 & 0.1989 & $99.48 \pm 0.25$ \\
\hline Brand II & 0.2 & 0.1997 & $99.85 \pm 0.16$ \\
\hline
\end{tabular}

\section{Precision Study:}

The precision of the method was determined at three levels (10, 20 and $50 \mu \mathrm{g} / \mathrm{ml})$ and each concentration was injected thrice (intra-day precision) on the same day and the mean, standard deviation and relative standard deviation were calculated. The inter-day precision was calculated by injecting each of the concentration $(10,20$ and $50 \mu \mathrm{g} / \mathrm{ml})$ thrice on three consecutive days and there by the mean, standard deviation and relative standard deviation were calculated (Table 2).

Table 2. Precision Study.

\begin{tabular}{|c|c|c|c|c|c|}
\hline \multirow{2}{*}{ S No. } & \multirow{2}{*}{$\begin{array}{l}\text { Conc. } \\
(\mu \mathrm{g} / \mathrm{ml})\end{array}$} & \multicolumn{2}{|c|}{ Intra-day precision } & \multicolumn{2}{|c|}{ Inter-day precision } \\
\hline & & Mean* \pm SD & $\% \mathrm{RSD}$ & Mean* \pm SD & $\%$ RSD \\
\hline 1 & 20 & $612778.33 \pm 2637.639$ & 0.431 & $611941.25 \pm 2411.05$ & 0.394 \\
\hline 2 & 40 & $1226154.67 \pm 4267.821$ & 0.348 & $1223216.85 \pm 3449.47$ & 0.282 \\
\hline 3 & 60 & $1839312 \pm 16258.741$ & 0.884 & $1849224.56 \pm 18011.45$ & 0.974 \\
\hline
\end{tabular}

\section{Accuracy Study:}

Accuracy study was determined by the addition of a known amount of solution to the preanalysed sample and the resultant samples were injected in to the HPLC system. Results of recovery study are shown in Table 3.

Table 3. Accuracy Study.

\begin{tabular}{|c|c|c|c|c|}
\hline $\begin{array}{c}\text { Amount (\%) } \\
\text { of drug added } \\
\text { to analyte }\end{array}$ & $\begin{array}{c}\text { Theoretical } \\
\text { content } \\
(\mu \mathrm{g} / \mathrm{mL})\end{array}$ & $\begin{array}{c}\text { Mean } \\
\text { Conc. found } \\
(\mu \mathrm{g} / \mathrm{mL}) \pm S D\end{array}$ & \% Recovery & \% RSD \\
\hline 80 & 32 & $32.18 \pm 0.0458$ & 100.56 & 0.142 \\
\hline 100 & 40 & $39.63 \pm 0.10$ & 99.13 & 0.252 \\
\hline 120 & 48 & $47.89 \pm 0.261$ & 99.77 & 0.545 \\
\hline *Mean of three replicates.
\end{tabular}




\section{Results and Discussion}

Brimonidine was eluted on an Inertsil ODS 3V column (C18) using mobile phase Octane 1sulfonic acid sodium salt $(0.02 \mathrm{M})(\mathrm{pH} 3.5 \pm 0.05)$ and acetonitrile $(64: 36 \mathrm{v} / \mathrm{v})$ at a flow rateof $1 \mathrm{~mL} / \mathrm{min}$ with $\mathrm{UV}$ detection at $254 \mathrm{~nm}$. Brimonidine was eluted at $4.636 \mathrm{~min}$. The linearity was observed in the concentration range of $0.4-72 \mu \mathrm{g} / \mathrm{mL}$ with a regression equation $30719 \mathrm{x}-362.1$ and correlation coefficient 0.999 . The LOD and LOQ were found to be 0.0561 and $0.1848 \mu \mathrm{g} / \mathrm{mL}$ respectively.

The system suitability test was performed to ensure that the complete testing system was suitable for the intended application. The theoretical plates were found to be 6939 and asymmetry 1.05 . The method is precise (Interday $0.282-0.974$ ) and Intra-day $0.348-0.884$ ) and accurate $(0.142-0.545)$ as the RSD is less than $2 \%$. The percentage of purity of Brimonidine in commercial formulations was found to be 99.48 and 99.85 .

\section{Conclusion}

The proposed liquid chromatographic method is simple, rapid, reproducible and economical for the analysis of Brimonidine in pharmaceutical formulations and can be applied successfully for the quantitative analysis of Brimonidine in pharmaceutical formulations.

\section{References}

1. The Merck Index, An Encyclopedia Of Chemical, Drug's and Biologicals, Maryadele J.O. Neil.Eds, 14th edition, Published by Merck Research Lab, Division of Merck and co. Inc., Whitehouse Station, NJ: 2006,1375, 225.

2. Toris, C., Camras, C., Yablonski, M., American journal of ophthalmology 1999, 128 (1), 8 .

3. Manohar C. Sonanis, Rajput A.P, Int J Pharm Pharm Sci, 2011, 3(1), 145.

4. WU Hong-ying, WANG Wen-yi, Qilu Pharmaceutical Affairs 2008-10.

5. Mohammed Shahid Ali, Aamer Roshanali Khatri, Muhammad Imran Munir and Mohsin Ghori, Chromatographia 2009, 70 (3-4), 539.

6. A.Madhavi, A. Naidu, D. V. Subba Rao, P. Srinivasu, Chromatographia 2009.

7. Karamanos NK, Lamari F, Katsimpris J, Gartaganis S., Biomed Chromatogr. 1999, 13(1), 86.

8. Sherwin Jiang, Arvind K. Chappa, JoelW. Proksch. Journal of Chromatography B, 2009, 877, 107.

9. Prakash Bhagav, Pandurang Deshpande, Saurabh Pandey, Sajeev Chandran, Der Pharmacia Lettre, 2010, 2(3), 106.

10. Mahajan Anand1, Athensia Fonseca1, Gandhi Santosh V, Deshpande Padmanabh B, International Journal of PharmTech Research, 2010, 2(3),1376.

11. International Conference on Harmonization of Technical Requirements for Registration of Pharmaceuticals for Human Use (Nov. 6,) Validation of Analytical Procedures: Methodology, ICH Steering Committee, Geneva, Switzerland. 1996. 


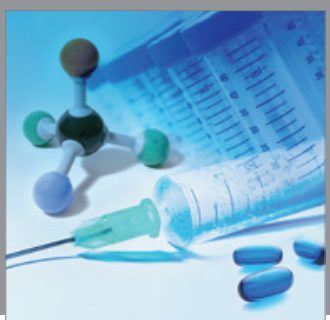

International Journal of

Medicinal Chemistry

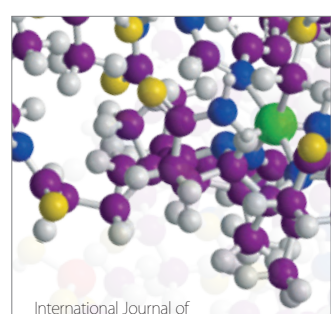

Carbohydrate Chemistry

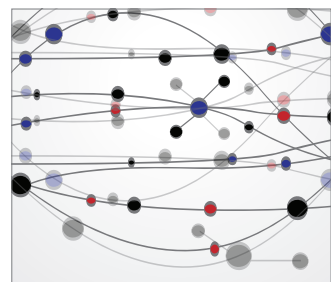

The Scientific World Journal
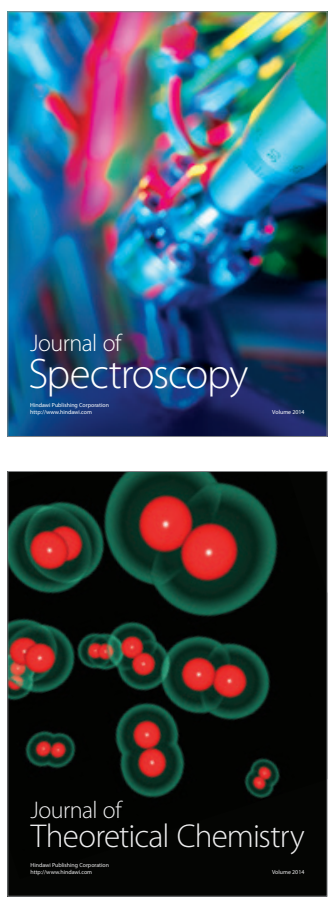
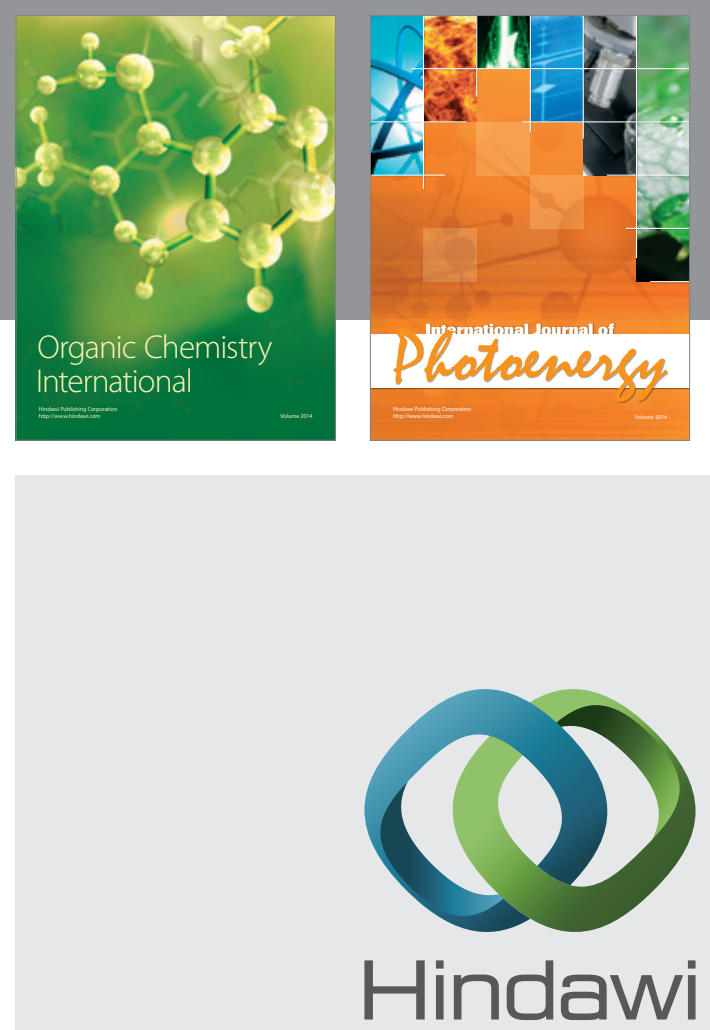

Submit your manuscripts at

http://www.hindawi.com
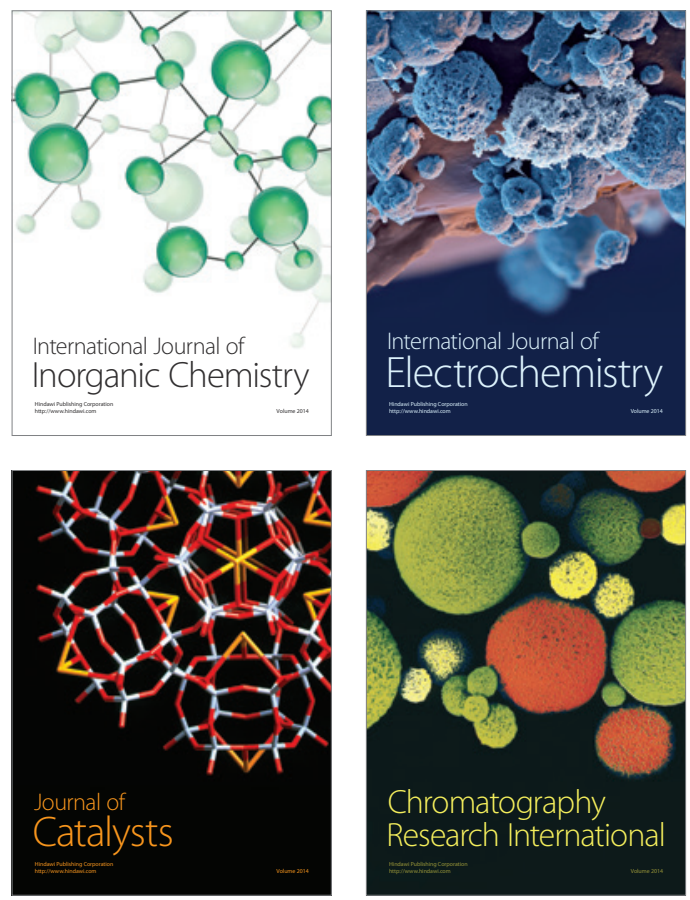
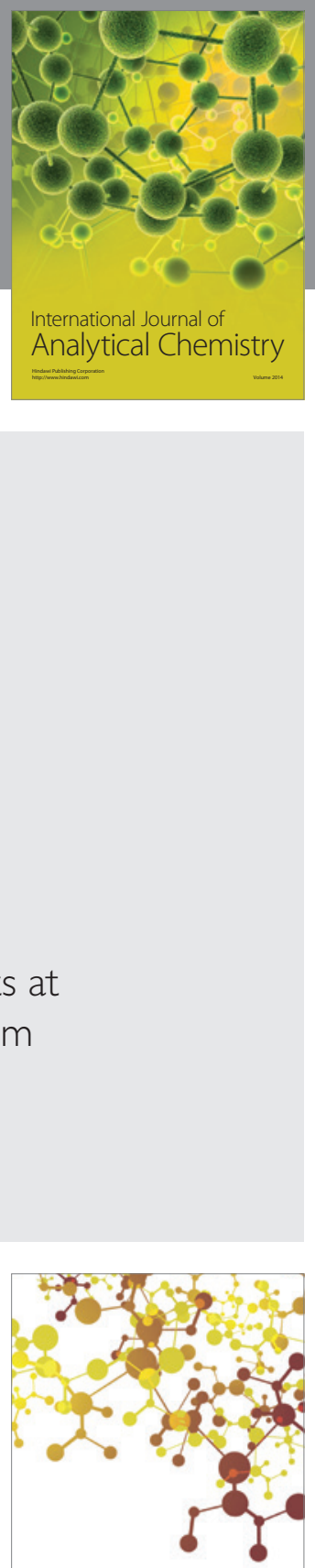

Journal of

Applied Chemistry
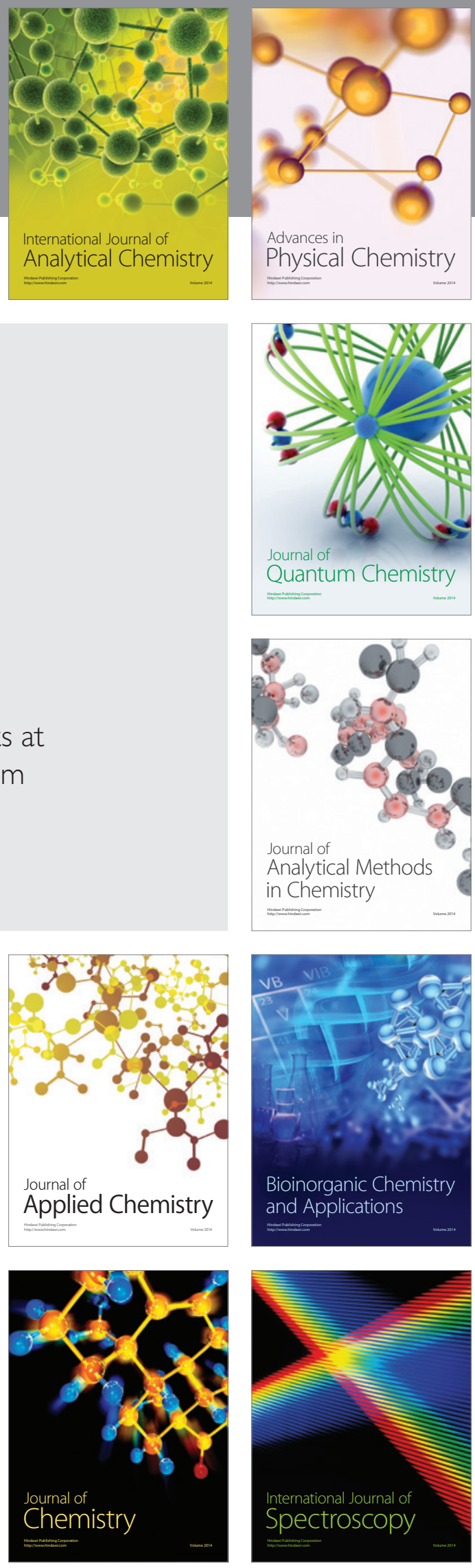